\title{
FAILURE MECHANISMS THAT CAUSE HIGH ELECTRICAL LEAKAGE IN MULTILAYER CERAMIC CAPACITORS
}

\author{
HIROFUMI IKEO, SANPEI SAKAMOTO, KEN SATO ${ }^{\dagger}$, HISAKAZU NISHIURA ${ }^{\dagger}$, and \\ KATSUHIRO OHNO \\ Kita-Itami Works, Mitsubishi Electric Corporation, Itami, Japan 664 \\ $\dagger$ Central Research Laboratory, Mitsubishi Electric Corporation, Amagasaki, Japan 661 \\ $\$$ Manufacturing Development Laboratory, Mitsubishi Electric Corporation, Amagasaki, Japan 661
}

\begin{abstract}
The causes of failure mechanisms of multilayer ceramic capacitors that result in zero resistance (shorts) or low resistance (high leakage) behaviour in the capacitors when the capacitors are subjected to low voltages have been studied. It has been found that failures resulted from the electrochemical reaction of electrode materials in the microscopic open pores which pass across a ceramic layer between inner electrodes and are filled with water containing $\mathrm{Cl}^{-}$ions. The mechanism found in this investigation has been applied to enable screening processes to be evolved for manufactured capacitors to eliminate the possibility of failure and hence to improve the reliability of circuits using multilayer ceramic capacitors.
\end{abstract}

\section{INTRODUCTION}

There are three types of typical failure modes in multilayer ceramic capacitors; electrical shorts or low resistance, open circuits failure, and finally capacitance value being out-of-tolerance. The most common of the three is the electrical short circuit or low resistance failure mode.

It has been reported by T. F. Brennan ${ }^{1}$ that in many cases multilayer ceramic capacitors failed insulation resistance testing at less than $1 / 10$ th of their rated voltage. Voids (small or large), microcracks, delaminations, impurities in the ceramic, migration of external electrode materials (e.g. silver), and contamination on the ceramic surface have all been considered as the causes of poor insulation resistance. ${ }^{2,3}$ However, failure due to low resistance at low voltage stress has not been examined.

In this paper, we describe the following: finding the conditions for insulation resistance failures; clarifying the materials responsible for the leakage by microanalysis; confirming a mechanism by electrochemical measurements; and proposing methods to reject failed capacitors during manufacture, in order to ensure high-reliability capacitor manufacturing.

The capacitors which we studied consisted of multiple layers of Pd metal electrodes with the inner electrodes separated by ceramic dielectric material (mainly barium titanate).

\section{ELECTRICAL BEHAVIOUR OF FAILED CAPACITORS}

Typical properties of leaky capacitors which failed in the reliability test were as follows:

1) Voltage-current characteristic at low voltages was ohmic as shown in Figure 1.

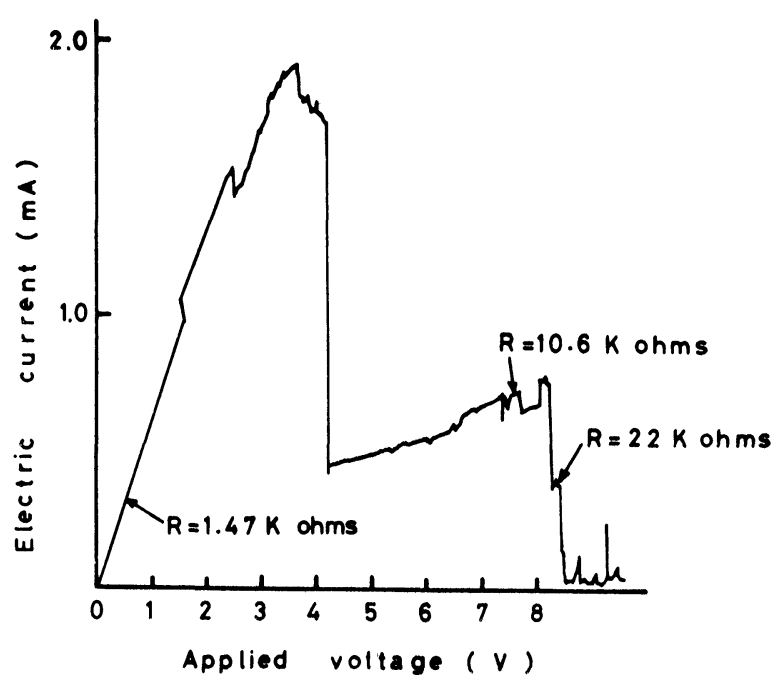

FIGURE 1 Voltage-current characteristic of failed capacitor. 
2) Most of the leaky capacitors recovered as the voltage was increased beyond several volts (they change discontinuously, with irreversible change, to the higher resistance level) as shown in Figure 1.

3) Temperature coefficients of resistance in the ohmic region were positive (about $+10^{-3} /{ }^{\circ} \mathrm{C}$ ).

4) Failed capacitors frequently recovered their insulation resistance at high temperature (above $+200^{\circ} \mathrm{C}$ ).

Most of the leakage failures took place at relatively low dc voltages and tended to depend on the specific batch of capacitors examined.

\section{REAPPEARANCE OF FAILURES}

Reappearance of failure tests were performed by the procedures as shown schematically in Figure 2.

Capacitors were boiled in water for several hours. Afterwards the capacitors were dried, and insulation resistancce was measured at the rated voltages. The boiled capacitors were classified according to the resistance level: below $10^{10} \mathrm{ohms}$ (rejected capacitors) and above $10^{10} \mathrm{ohms}$ (acceptable capacitors).

Every capacitor was subjected to dc voltage stresses from $0.25 \mathrm{~V}$ to $10 \mathrm{~V}$ in an atmosphere of $85 \% \mathrm{RH}$ and at $+85^{\circ} \mathrm{C}$ in a thermo-hygrostat. Under voltage stresses, some of the capacitors failed at less than $10^{4} \mathrm{ohms}$ for applied voltage between $0.5 \mathrm{~V}$ and $3 \mathrm{~V}$ as shown in Figures 3 and 4 . Acceptable capacitors after boiling did not fail at any voltage. The electrical properties of failed capacitors in this reappearance test were the same as those of the failed capacitors in the reliability test. This reappearance test method was evolved by taking account of the electrical properties and the environment of the failed capacitor.

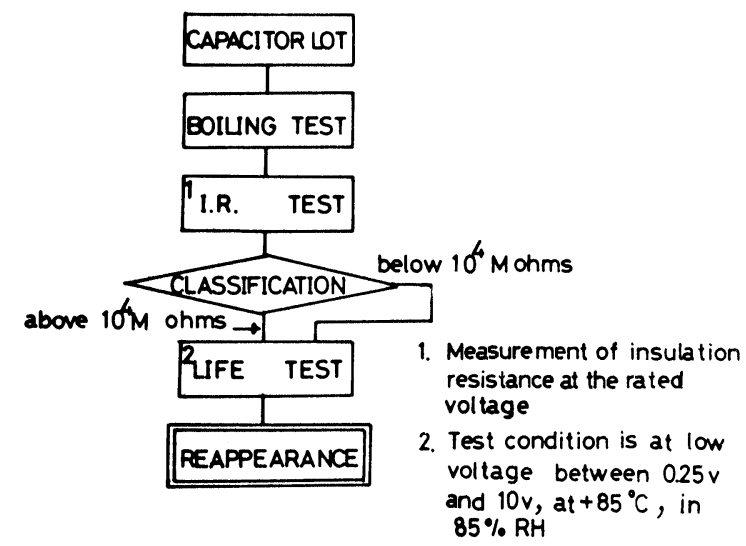

FIGURE 2 Reappearance test flow chart.

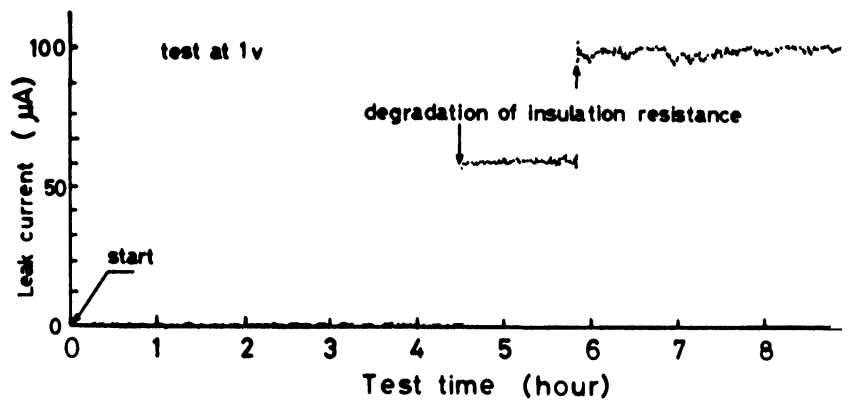

FIGURE 3 Abrupt degradation of insulation resistance at $1 \mathrm{~V}$, at $+85^{\circ} \mathrm{C}$ and in $85 \% \mathrm{RH}$.

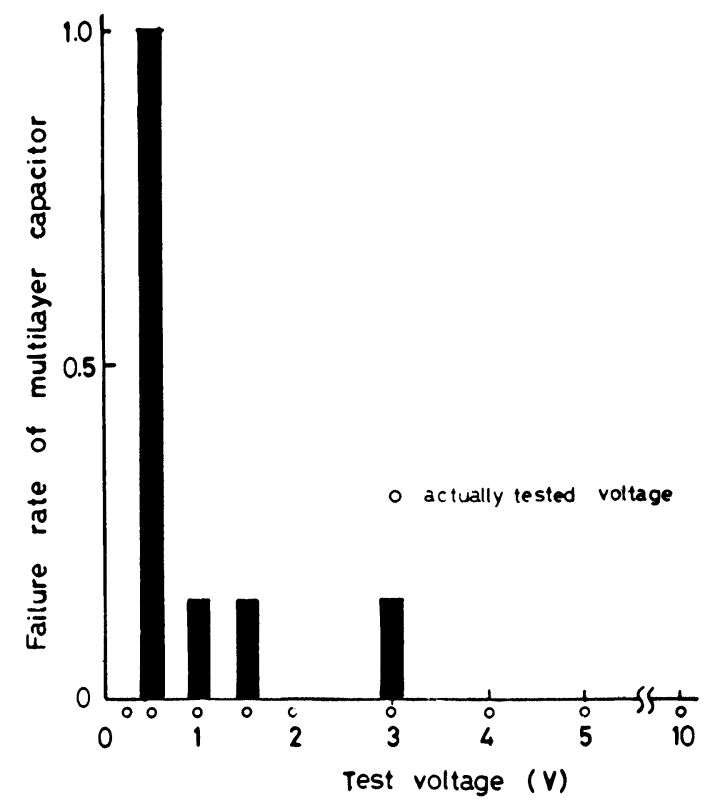

FIGURE 4 Failure rate at dc voltage stresses from $0.25 \mathrm{~V}$ to $10 \mathrm{~V}$ under high temperature and humidity

\subsection{Weibull Distribution of Failure}

Weibull distributions were plotted for the failed capacitors in two cases. The first was for the failures in the reappearancce test, and the second was for the failures in the device reliability test. From Figure 5, the shape parameter $m$ of the Weibull distribution can be seen to be 0.3 to 0.4 in both cases. It is therefore possible to detect failed capacitors because every failed capacitor belongs to a decreasing failure rate group. 


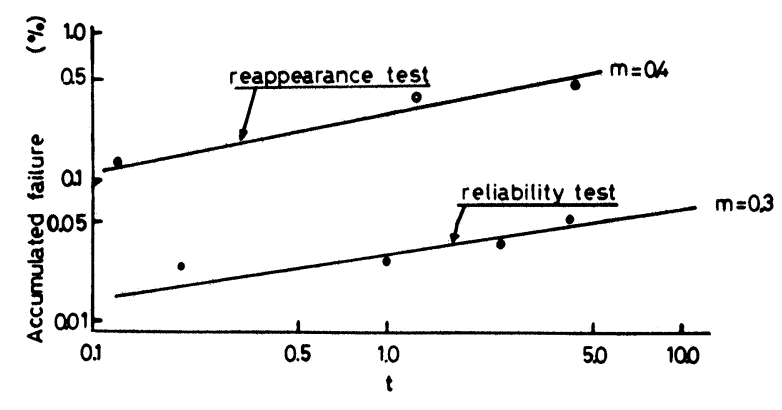

FIGURE 5 Weibull distribution analysis of failed capacitors.

\subsection{Location of Leakage Path}

The leakage path of the failed capacitor was investigated by three steps.

First step: After confirming that there was no leakage on the ceramic surface, the individual inner electrodes were isolated by removing one of the outer electrodes. The leaky ceramic layer was determined by measuring the resistance between each isolated electrode and the other outer electrode as shown schematically in Figure 6.

Second step: The ceramic was planed down parallel to the inner electrode plate by sand paper or sand/air abrasion, until the dielectric layer between the electrodes (1 and $1^{\prime}$ - in Figure 6) appeared. One of the inner electrode plates across the dielectric layer was then exposed by using a narrow beam sand/air abrasion system and afterwards the outer electrode which had been removed by the first step was reconnected using silver paste. Careful removal of the electrode plate a

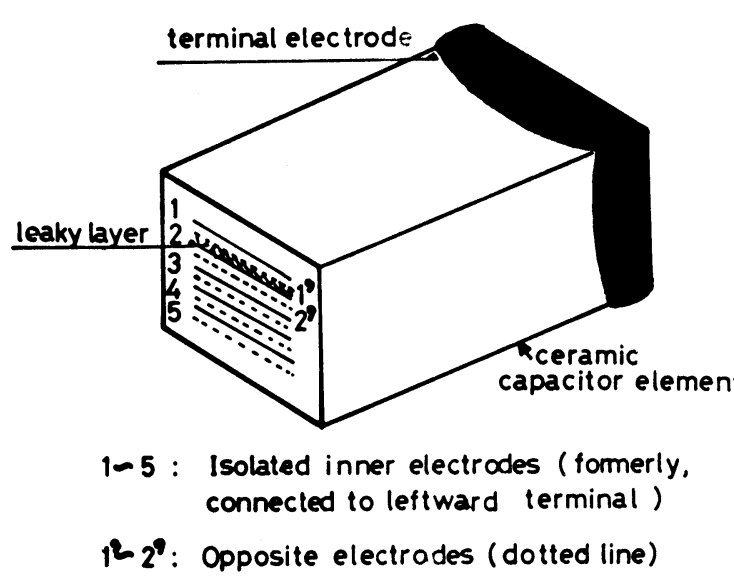

FIGURE 6 Procedure to clarify leakage layer (in this case leakage layer is between $1^{\prime}$ and 2). little at a time, whilst watching the current across the dielecrtric, was performed until the observed resistance suddenly became infinite. This location, just before the resistance became infinite, is the macroscopic high leakage portion of the dielectric (as shown schematically in Figure 7).

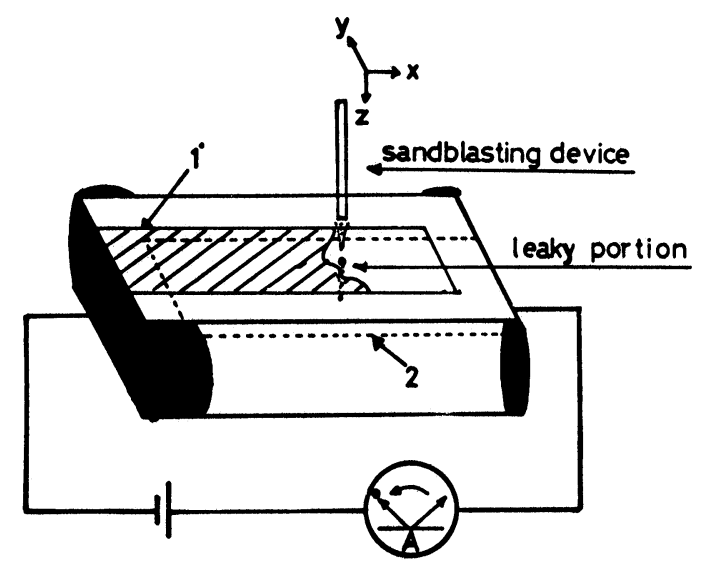

FIGURE 7 Procedure to clarify macroscopically leaky portion of capacitor.

Third step: When the electron beam of a Scanning-Electron Microscope (SEM) is allowed to impinge on the insulator, a charging phenomenon occurs. However the charging phenomenon does not occur if the dielectic exhibits high leakage (see Figure 8 ). It is thus possible to determine the exact position of the high leakage portion of the dielectric exposed in step 2 .

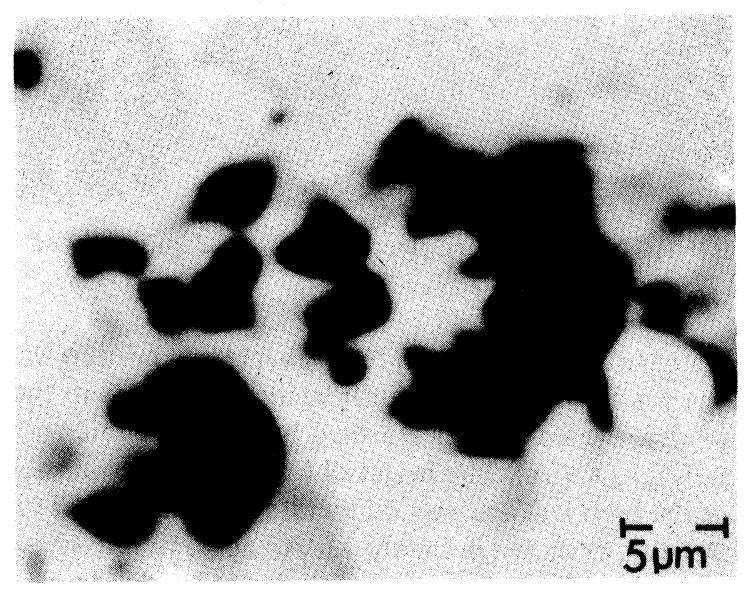

FIGURE 8 Charging image by SEM (insulation resistance of sample is $80 \mathrm{ohms}$ ). 


\subsection{Structure of High Leakage Portion and the Materials Involved}

After charging, the ordinary secondary electron image of the SEM was used to study the structure of the high leakage portions as shown in Figures 9 and 10. The

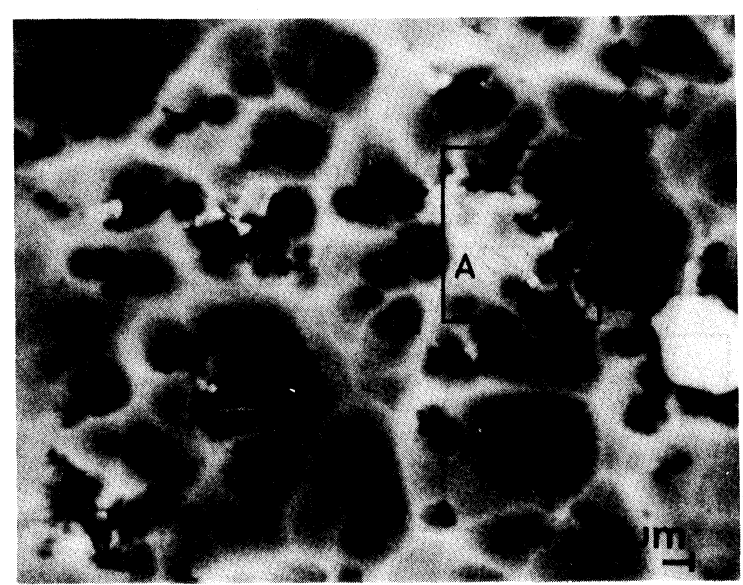

FIGURE 9 Secondary electron image of Figure 8.

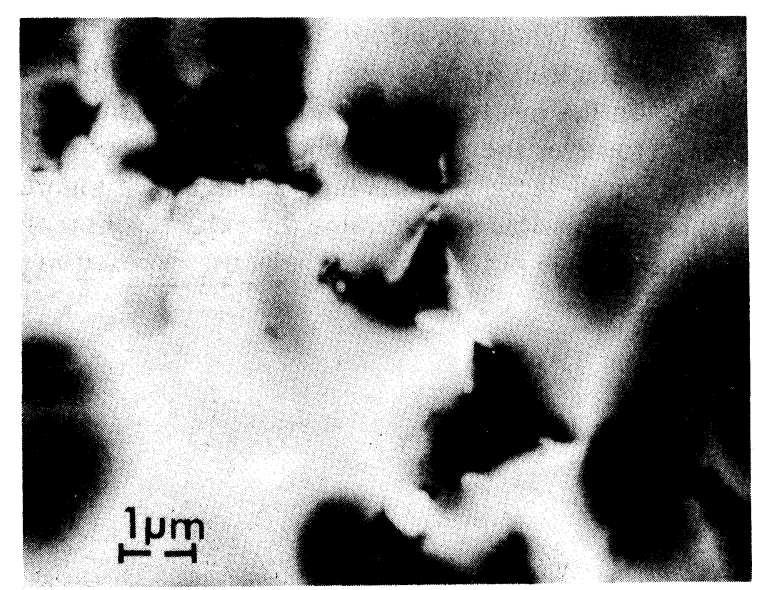

FIGURE 10 Secondary electron image (magnification of portion $A$ in Figure 9).

existence of small voids in the high leakage portion was thus confirmed. Subsequently element analysis in the vicinity of voids was performed by an X-ray micro analyzer (XMA). The material found to be responsible for the high leakage was $\mathrm{Pd}$ metal together with $\mathrm{Cl}^{-}$in the voids as shown in Figure 11. An agglomerate phase containing $\mathrm{Ca}$ was also found near the voids. After bombarding the high leakage portion with $\mathrm{Ar}^{+}$ions step by step, it was also confirmed by SEM-XMA that

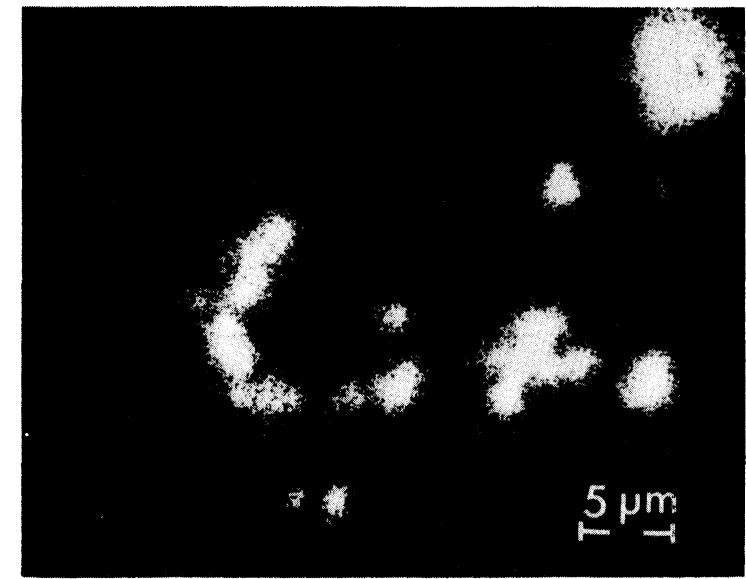

FIGURE 11 Characteristic Pd L $\alpha$ X-ray image.

the leakage path branched and penetrated more than one dielectric layer. The concentration of $\mathrm{Cl}^{-}$ions together with Pd metal was found to be about $0.1 \mathrm{wt} \%$. A failed capacitor having relatively high insulation resistance contained smaller quantities of $\mathrm{Pd}$ than failed capacitors having low insulation resistance.

\section{FAILURE MECHANISMS}

On the basis of the experimental facts, the following processes are suggested.

1) Formation of the microscopic leakage path between inner electrodes during manufacturing or during assembly processes.

2) Penetration into the microscopic leakage path, already contaminated with $\mathrm{Cl}^{-}$ions, by water from the outside of the capacitor.

3) Deposition of inner electrode material into the microscopic leakage path based on an electrochemical reaction of the inner electrode metal at low dc voltages.

\section{CONFIRMATION OF FAILURE MECHANISMS}

\subsection{Penetration of Water into the Microscopic Leakage Path}

From micro-analysis of the failed capacitors, it has been found that there were deposits of $\mathrm{Pd}$ in the voids in the microscopic path. In addition to this, whether water penetrates into the ceramic from the surface of the 
capacitors or not was examined by a penetration method using a fluorescent dye solution. The traces of the fluorescent dye were confirmed in the interior of the ceramic layer. It was thus found that the microscopic path was open to the atmosphere.

\subsection{Pd Migration}

In order to study Pd migration, the dissolution of palladium was measured as a function of electrochemical electrode potential in water and in aqueous solutions of $\mathrm{Na}_{2} \mathrm{SO}_{4}, \mathrm{NaNO}_{3}$, and $\mathrm{NaCl}$. The relationships between the applied voltage $V_{a}$, the current density $J$, the anode potential $E_{a}$ and the cathode potential $E_{c}$, are shown in Figure 12 for the case of aqueous $\mathrm{NaCl}$ soltuion. To measure the minimum dissolution voltage for Pd, the current (1) in Figure 12 is shown in Figure 13 on an enlarged scale. The beginning of the current increase appears around $0.3 \mathrm{~V}$. This anode potential is equivalent to the applied voltage of about $0.5 \mathrm{~V}$ given in Figure 12 .

As an attempt to observe $\mathrm{Pd}$ dissolution directly, two sheets of filter paper containing $1 \mathrm{~N} \mathrm{NaCl}$ solution were sandwiched between Pd metal plates, and a low dc voltage was applied to the Pd plates. As expected, one could observe directly the Pd migration from the colour change (black) on the paper at the cathode. Pd migration was observed at $1.5 \mathrm{~V}$, but applied voltages above $3 \mathrm{~V}$ no longer gave $\mathrm{Pd}$ dissolution. $\mathrm{Pd}$ migration in the region of $0.5 \mathrm{~V}$ to $3 \mathrm{~V}$ coincided with the voltage region in which capacitors failed.

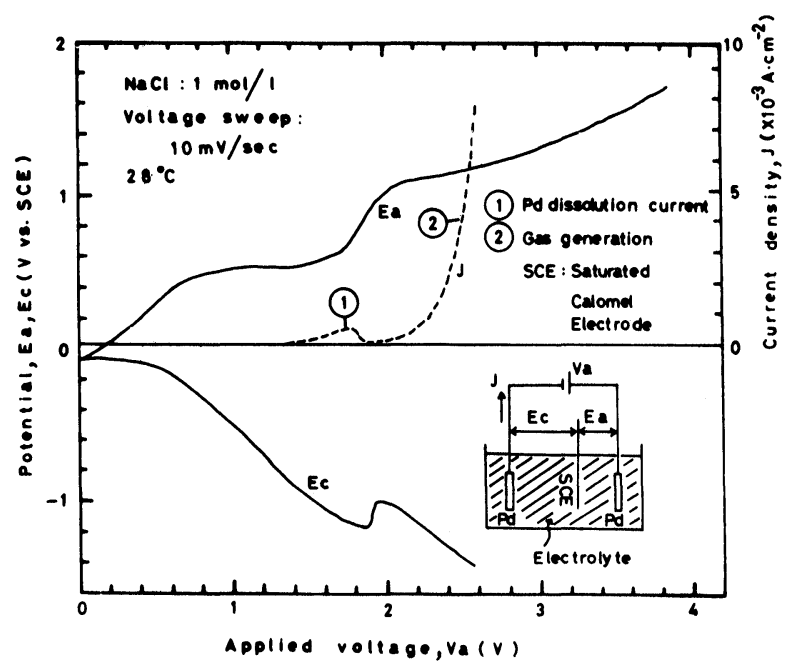

FIGURE 12 Electrochemical reaction test in an aqueous $\mathrm{NaCl}$ solution.

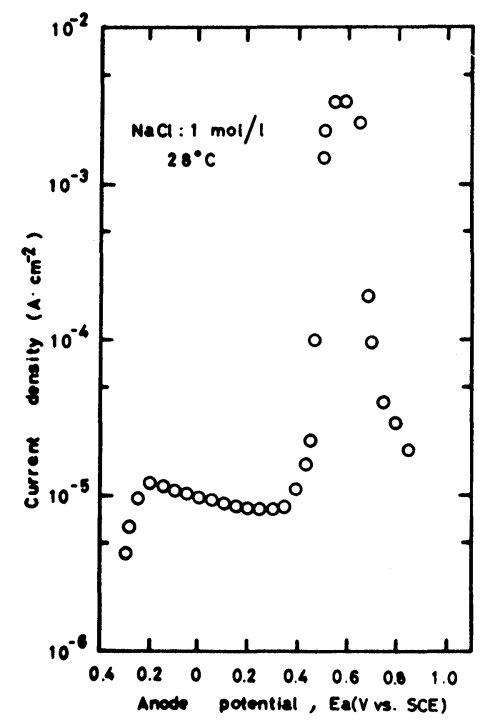

FIGURE 13 Enlargement of current (1) in Figure 12.

\subsection{Chlorine Ion Effects}

It is certain that $\mathrm{Cl}^{-}$ions play an important part in the failure of capacitors. Several capacitors were therefore boiled in $1 \mathrm{~N} \mathrm{NaCl}$ for several hours. The resulting capacitors were classified into two groups: those showing a resistance above $10^{10} \mathrm{ohms}$ on the rated voltage test and those showing resistance below $10^{10}$ ohms. After the capacitors were dried, life tests were performed at two voltages, $0.5 \mathrm{~V}$ and $1.5 \mathrm{~V}$, in an atmosphere of $85 \% \mathrm{RH}$ and at $+85^{\circ} \mathrm{C}$. Results are shown in Figure 14 and can be classified into two

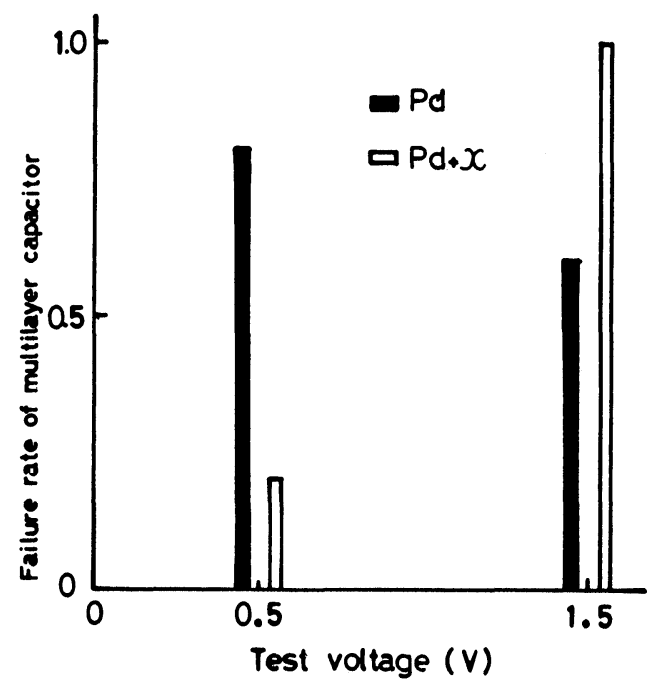

FIGURE 14 Dependence on test voltage of failure rate (for two cases: $\mathrm{Pd}$ inner electrode, $\mathrm{Pd}+x$ inner electrode). 
groups: those associated with capacitors having electrodes of pure Pd metal and those associated with capacitors having electrodes in which the Pd is contaminated by a small amount of another unknown metal represented by $x$ in Figure 14 .

The fact that the failure rate of the Pd electrodes contaminated with small amounts of another metal is much higher at $1.5 \mathrm{~V}$ than $0.5 \mathrm{~V}$ is interpreted as showing that the voltage migration depends on the electrode material. Furthermore measurements of the time taken to arrive at failure gave figures of between one minute to 45 minutes for capacitors boiled in $\mathrm{NaCl}$ solution and 10 minutes to 10 hours for those boiled in water.

It can be seen that boiling in $\mathrm{NaCl}$ solution has an accelerating effect on the failure of insulation resistance in the capacitors.

\section{SCREENING METHODS FOR CAPACITORS}

It has been suggested that in a capacitor, leakage paths may be formed by the electrochemical reaction of Pd (the inner electrode material), provided that there exists small voids of microcracks passing through the dielectric, into which water containing $\mathrm{Cl}^{-}$ions can penetrate. These leakage paths result in low voltage failures. It was thus possible to establish screening methods for capacitors as follows:

1) An electrical test using a voltage about ten times the rated voltage.

2) A boiling water or $\mathrm{NaCl}$ solution test in which the capacitors are immersed for several hours.

3) A low dc voltage life test under high temperature and high humidity conditions $\left(85^{\circ} \mathrm{C}\right.$ and around $85 \% \mathrm{RH})$.

\section{IMPROVEMENTS TO CERAMIC CAPACITOR MANUFACTURING}

It has been shown that the most important defects leading to the degradation of insulation resistance are small voids and microcracks leading from the outside of the capacitor through the inner electrodes. The causes of these defects are very complicated. It is suggested that the appearance of agglomerate phases in the ceramics, as found by XMA analysis must be avoided, since the difference in thermal expansion between the two phases may cause microcracking. Contamination by $\mathrm{Cl}^{-}$ions must also be eliminated because $\mathrm{Pd}$ dissolution at low dc voltage is increased in the presence of $\mathrm{Cl}^{-}$ions.

\section{CONCLUSIONS}

The leakage mechanism causing failure in ceramic capacitors has been studied using various techniques. The existence of small voids or microcracks passing through the dielectric, the presence of chlorine contamination in water that has penetrated into the capacitors through the microcracks and the subsequent effect of chlorine on the dissolution of Pd of the inner electrodes are all contributions to the leakage mechanism. Furthermore it has been shown that the dissolution of Pd can occur at low voltage stresses in the presence of chlorine ions.

As a result three screening tests have been suggested for detecting possible failures in capacitors.

With regard to improving the manufacturing of ceramic capacitors, it is noted that it is important to eliminate $\mathrm{Cl}^{-}$ion contamination, open pore structures in the ceramic and any agglomeration phases in the ceramic.

\section{ACKNOWLEDGEMENTS}

The authors wish to express their great appreciation to Messrs. Isoichi Kusajima, Tadashi Katashima and Yasuhiro Nakanishi of the Himeji Works for their helpful and stimulating suggestions. We would also like to thank Dr. Kyoichi Shibayama and Dr. Takeshi Koyama of the Kita-Itami Works, and Mr. Yozo Nakajima of the Central Research Laboratory for their continuous encouragement throughout this study. We are also indebted to Messrs. Yoshihiro Ogata and Hideaki Miyoshi of the Central Research Laboratory for microanalysis and for electro-chemical measurements, respectively.

\section{REFERENCES}

1. T. F. Brennan, "Ceramic Capacitor Insulation Resistance Failures Accelerated by low Voltage", 16th Annual Proceedings of Reliability Physics Symposium, pp. 69-74 (1978).

2. J. Piper, "Microstructure and Reliability of Ceramic Chip Capacitors", Proceedings International Microelectronics Symposium, pp. 4A2-1-4A2-10 (1972).

3. G. J. Ewell, and W. K. Jones, "Encapsulation, Sectioning, and Examination of Muitilayer Ceramic Chip Capacitors", Proceedings IEEE-EIA, Electronics Components Conference, pp. 446-451 (May 1977). 

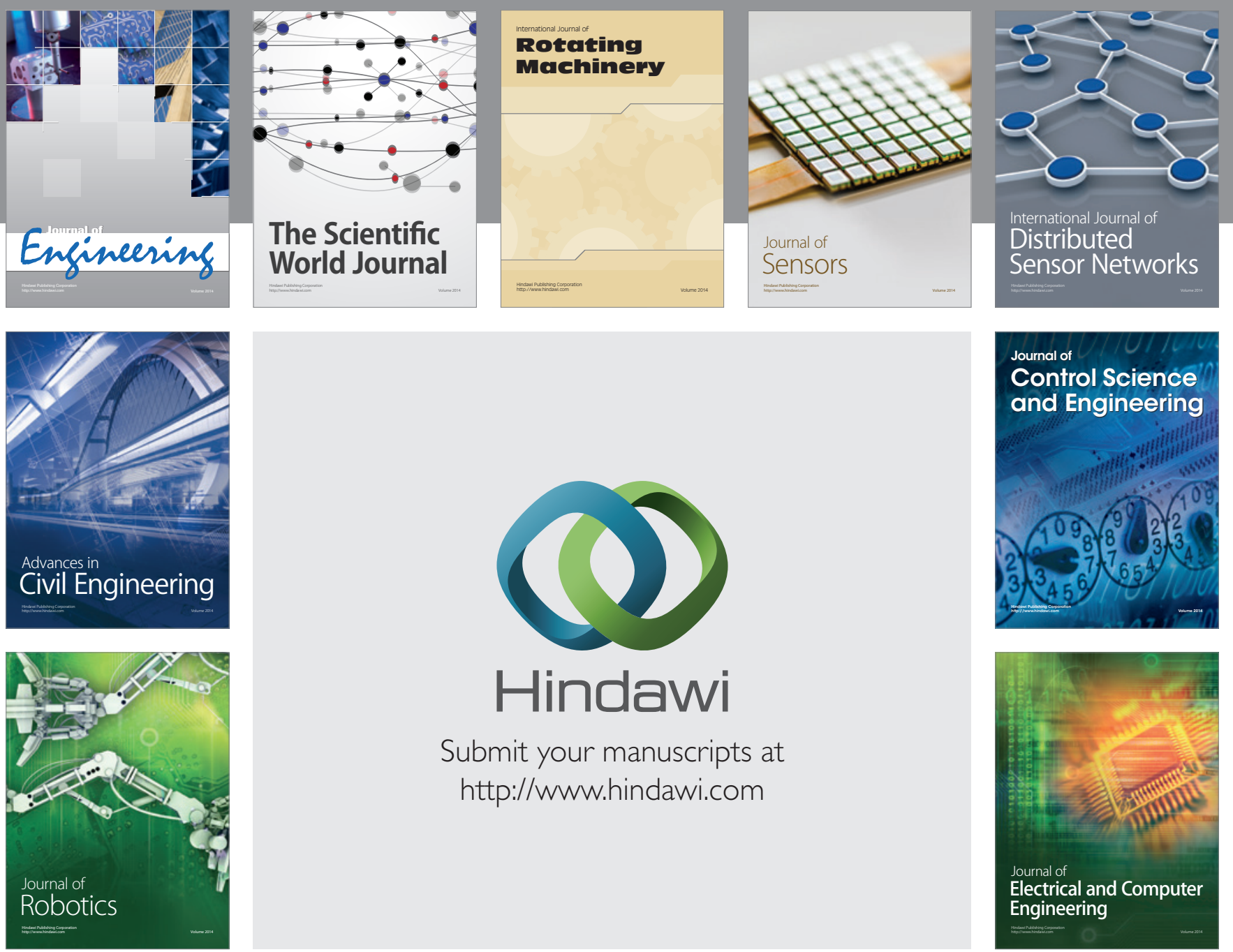

Submit your manuscripts at

http://www.hindawi.com
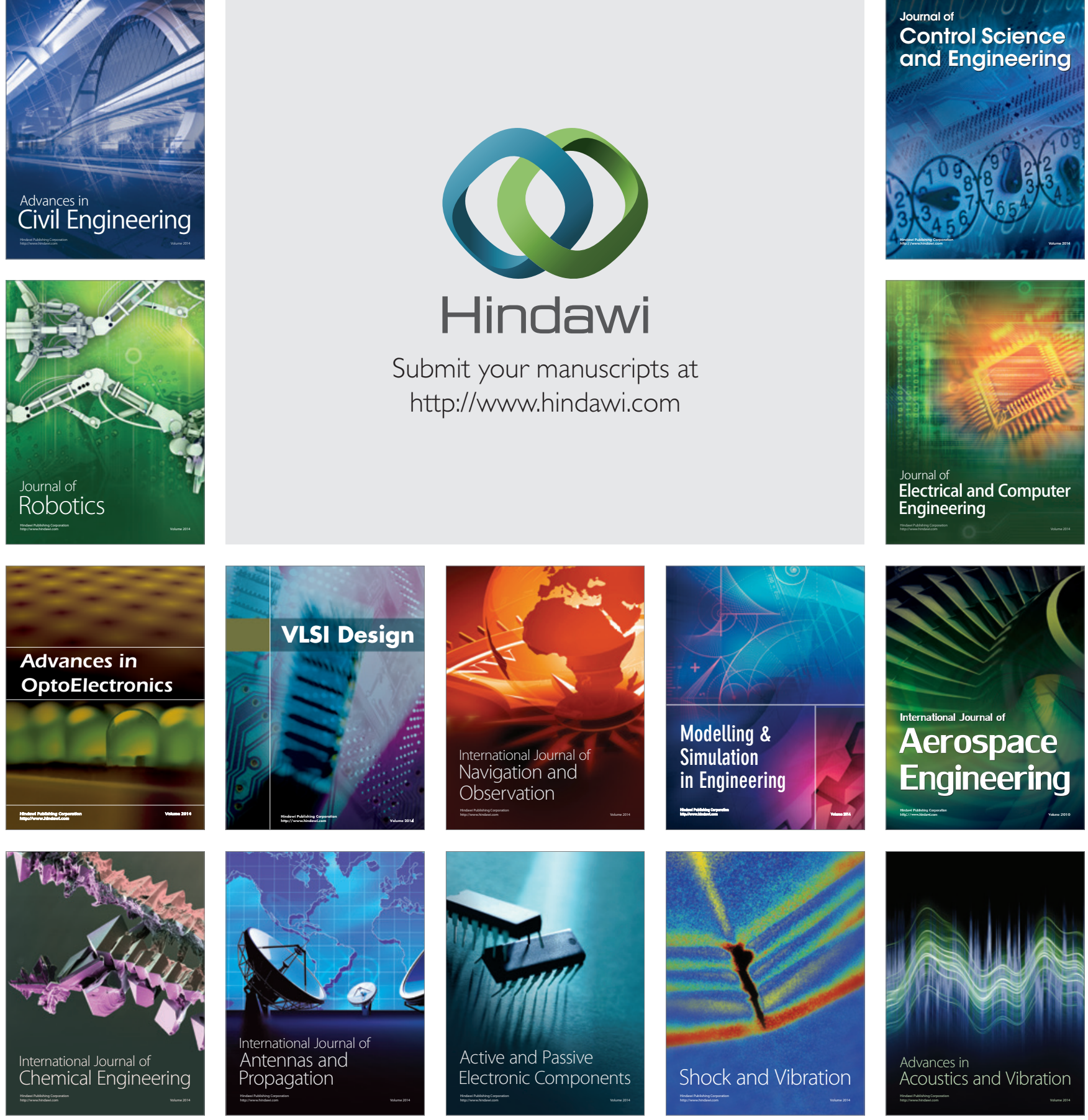